\title{
A Micro-Force-Tracking System Based on PVDF Static Micro-Force Sensor and Fuzzy-PID Control Method
}

\author{
Zhiyong Sun ${ }^{1, \mathrm{~b}}$, Wenlin $\mathrm{Chen}^{2}$,Yunquan $\mathrm{Su}^{1}$ and Lina Hao ${ }^{1, \mathrm{a}}$
}

\author{
${ }^{1}$ School of mechanical Engineering and Automation Northeastern University, Shenyang Liaoning \\ Province, China
}

\author{
${ }^{2}$ School of Resource and Civil Engineering, Northeastern University, Shenyang Liaoning Province, \\ China \\ ahaolina@me.neu.edu.cn (corresponding author), bsunzyymmnz@126.com
}

Keywords: Fuzzy-PID, PVDF, micro-force sensor, inverse model, close-loop control

\begin{abstract}
This article is intended to design a static micro-force sensor with a simple structure employing the polymer material PVDF (polyvinylidene fluoride) film as its sensing element, and will carry out some micro-force tracking tests. During the tracking tests, this paper employs a Fuzzy-PID control method and an ordinary PD control method to control the system, and will also analyze the results of them.
\end{abstract}

\section{Introduction}

Force sensing technology has been developing rapidly in the field of industrial robot applications, and this technology could also be used in micro-assembly and the cell-injection process. Due to the fact that the micro-force affects the successful rate of micro assembly and the survival rate of injected-cells directly[1], so a high sensitive static micro-force senor and its force-control system is in urgent need. In[2], Sung-Yong Cho et al. developed a strain gauge sensor with a needle at its end as a terminal manipulator to pierce the cells. In[3], Zesch et al using an AFM cantilever equipped with a piezoresestive sensor to push silicon block on a planar substrate with a micromanipulator. In [4], Yantao Shen et al. developed a high sensitive micro-force sensor based on PVDF (polyvinylidene fluoride), and applied it into erecting micro-mirrors. $\operatorname{In}[5], \mathrm{Yu}$ et al. finished cell-injection with a PVDF sensor and on-line identification method.

Reference [2] yielded some results, however, the circumstantial temperature affects the accuracy of strain gauge a lot, and this kind of strain gauge cost highly. Reference [4] and [5] employed PVDF films and some complicated physical circuits as their sensors, but the signal of them can not stay for a long time. This paper, based on the previous work, develops a static PVDF sensor employing the inverse-model algorithm with a simple physical circuit, and designs a Fuzzy-PID controller, then uses them to complete one micro-force tracking test.

This paper is structured as follows: section II will develop the static PVDF micro force sensor, section III will design the fuzzy-PD controller, the section IV will set up a micro-force tracking system with the static PVDF micro-force sensor and some control methods, and then will give some test results. The section $\mathrm{V}$ will give the summary of this paper.

\section{Design of Static PVDF Micro-force Sensor}

Electro-mechanical Model of PVDF Sensor's Physical System. PVDF as a piezoelectric material has a relatively low elastic modulus, high electromechanical coupling coefficient and low cost. Reference [4] provided a model of one dimensional PVDF film, the thickness of the film is too thin compared with its width and length, therefore, the strain along the width direction can be neglected. According to our previous work [6], the transfer function of PVDF film shown in Fig.1 is Eq.1, and the one of the magnitude-changeable charge amplifier circuit shown in Fig.2 is Eq.3. The whole transfer function of the physical PVDF sensor can be obtained as $T(s)=T_{1} \times T_{2}$, shown in Eq.4. The parameters in $\mathrm{B}$ are as follows: $\mathrm{A}=\mathrm{L} \times \mathrm{W}$ where $\mathrm{W}$ means the width of PVDF film and $\mathrm{L}$ stands for its length, $H$ stands for the thickness, $C_{p}$ stands for the capacitance, $d_{31}$ stands for the piezoelectric coefficient, $\varepsilon_{33}^{\mathrm{T}}$ is the dielectric constant and $\mathrm{I}_{\mathrm{zz}}$ stands for the moment of inertia. 


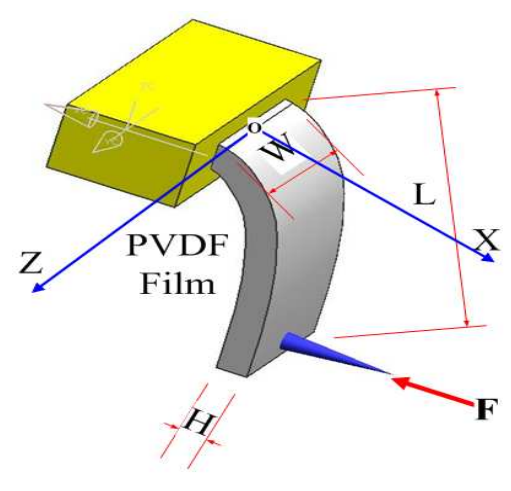

Fig. 1. Structure of PVDF sensor

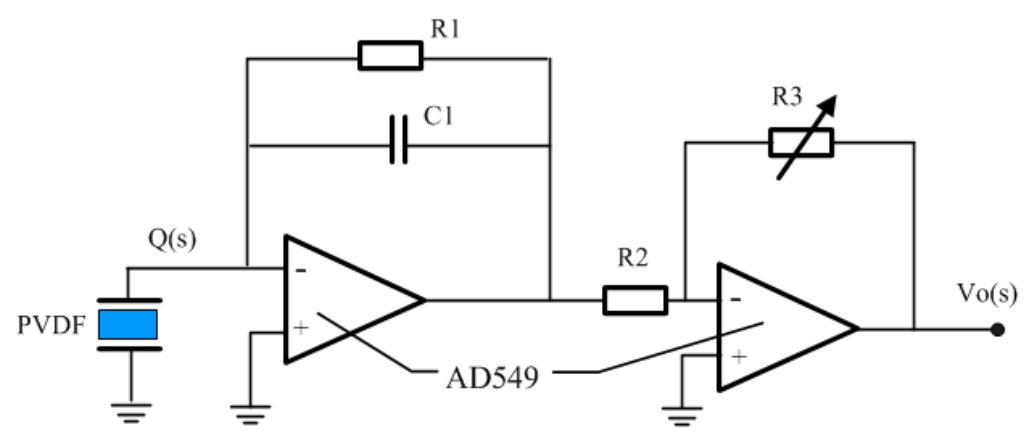

Fig. 2. Structure of the physical circuit

$$
\begin{aligned}
& \mathrm{T}_{1}(\mathrm{~s})=\frac{\mathrm{F}(\mathrm{s})}{\mathrm{Q}(\mathrm{s})}=\mathrm{B} \\
& \mathrm{B}=\frac{d_{31} \mathrm{C}_{p} \mathrm{ALH}^{2}}{4 \mathrm{I}_{z z}\left(\varepsilon_{33}^{\mathrm{T}} \mathrm{A}+\mathrm{C}_{p}\right)} \\
& \mathrm{T}_{2}=\frac{\mathrm{Vo}(\mathrm{s})}{\mathrm{Q}(\mathrm{s})}=\frac{\mathrm{R}_{3} \mathrm{R}_{1} s}{\mathrm{R}_{2}\left(\mathrm{R}_{1} \mathrm{C}_{1} s+1\right)} \\
& \mathrm{T}(\mathrm{s})=\frac{\mathrm{Vo}(\mathrm{s})}{\mathrm{F}(\mathrm{s})}=\frac{\mathrm{BR}_{3} \mathrm{R}_{1} s}{\mathrm{R}_{2}\left(\mathrm{R}_{1} \mathrm{C}_{1} s+1\right)}
\end{aligned}
$$

Sensor's Inverse Model Controller and Its Calibration. The inverse model is shown in Eq.5, and the inverse controller can be designed as Eq. 6 according to our previous work [6-8], here, $\mathrm{R}_{2}, \mathrm{R}_{3}$ and $\mathrm{B}$ are all included in the proportional factor $\mathrm{K}$, therefore the design parameters are only related to the $\mathrm{R}_{1}$ and $\mathrm{C}_{1}$, and one can change the factor $\mathrm{K}$ as he/she needs in the experiments.

$$
\begin{aligned}
& \mathrm{T}_{\text {inv }}(\mathrm{s})=\frac{\mathrm{R}_{2}}{\mathrm{R}_{3}}\left(\frac{C_{1}}{\mathrm{~B}}+\frac{1}{\mathrm{R}_{1} \mathrm{Bs}}\right) \\
& \mathrm{T}_{\text {control }}(\mathrm{s})=\frac{\mathrm{K}}{\mathrm{R}_{1} \mathrm{~s}}+\mathrm{KC}_{1}
\end{aligned}
$$

During the calibration of the PVDF sensor, $R_{2}=10 \mathrm{~K} \Omega, \mathrm{R}_{3}=100 \mathrm{~K} \Omega, \mathrm{K}=10$, and the filter is one $50 \mathrm{HZ}$ low-pass filter, the parameters of PVDF film are as follows: $\mathrm{W}=0.0123 \mathrm{~m}, \mathrm{~L}=0.02971 \mathrm{~m}$, $\mathrm{H}=60 \mu \mathrm{m}, \mathrm{C}_{\mathrm{p}}=0.2 \times 10^{-9} \mathrm{~F}$. The devices of calibration are shown in Fig.3, one can get the relationship between the output signal $(\mathrm{V})$ and the input signal $(\mu \mathrm{N})$ illustrated in the Fig.4 when the xyz-positioning table carries the PVDF sensor to push the fixed GS-10 sensor. The linearity error of the static sensor is about $6 \%$, and its resolution can reach $\mu \mathrm{N}$ level.

\section{Design of Fuzzy PID Control Method}

Reasons for Employing Fuzzy-PID Control. The accuracy of force-tracking is usually affected by the variable factors such as input signals, complex contact environment and also the circumstantial noise. In order to get high precision, a proper control method is required. Adaptive control is available in most conditions, it identifies the parameters of the complicated environment continuously, however, the accurate parameters depend on precise measurement of the inputs and outputs of the controlled plant, it is hard to do this when it comes to micro-scale objects and this method needs additional devices. Though a computer can not do this well, experienced people can 
make proper decisions to manage it. By employing these people's ideas, one can develop a Fuzzy-PID controller due to the very circumstance, this algorithm needs less equipments and it works effectively.

Fuzzy-PID Controller Design. In this paper, a Fuzzy-PID controller is designed as a two-input and two-output one due to the fact that the XYZ-positioning table worked here is a mechanical integration system. Here the two inputs are the error of the force-tracking and its change ratio separately, the outputs are $\Delta \mathrm{K}_{\mathrm{p}}$ and $\Delta \mathrm{K}_{\mathrm{d}}$ which vary according to the fuzzy reasoning tables, so the

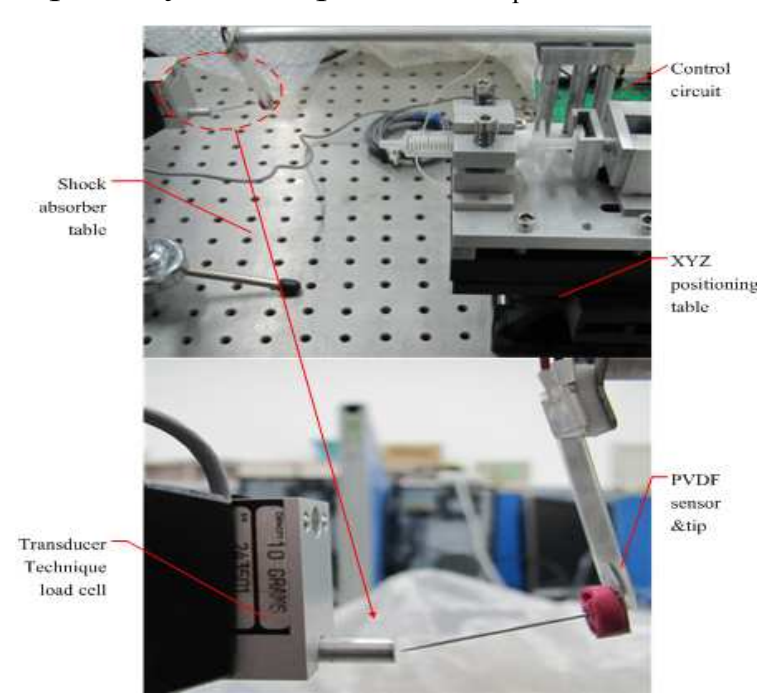

Fig. 3.The devices for calibration

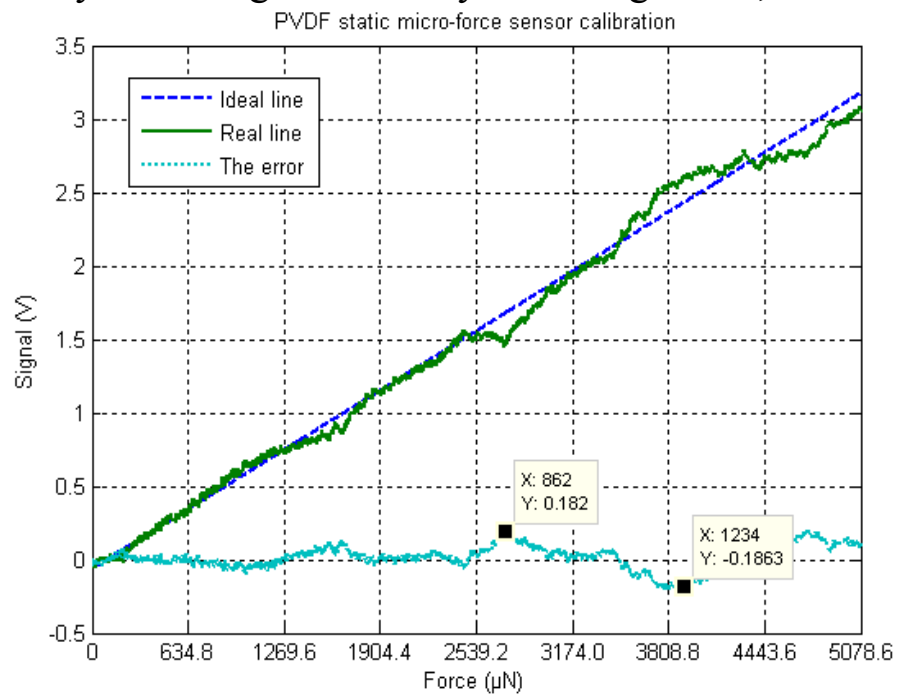

Fig. 4.The linearity calibration of PVDF static micro-force sensor

controller designed here is a Fuzzy-PD controller. The block diagram of the whole system is shown in Fig.5, where $K_{e}$ and $K_{c}$ are the mutable coefficients used to change the magnitude of e and $e_{c}(\dot{e})$, here $\mathrm{e}=\mathrm{F}_{\mathrm{e}}-\mathrm{F}_{\mathrm{d}}$. Defining the range of the signals e, $\mathrm{e}_{\mathrm{c}}, \Delta \mathrm{K}_{\mathrm{p}}, \Delta \mathrm{K}_{\mathrm{d}}$ as fuzzy sets, this paper obtains the expression as e, $\Delta \mathrm{K}_{\mathrm{p}}, \Delta \mathrm{K}_{\mathrm{d}}=\{\mathrm{NB}, \mathrm{NM}, \mathrm{NS}, \mathrm{ZO}, \mathrm{PS}, \mathrm{PM}, \mathrm{PB}\}$, and $\mathrm{e}_{\mathrm{c}}=\{\mathrm{NB}, \mathrm{NS}, \mathrm{ZO}, \mathrm{PS}, \mathrm{PB}\}$, where NB stands for negative big, NM negative middle, NS negative small, ZO means zero or no change, PS positive small, PM positive middle, PB positive big. In digital form, its range can be expressed as $\Delta \mathrm{K}_{\mathrm{p}}, \Delta \mathrm{K}_{\mathrm{d}}$, $\mathrm{e}=\{-6,-4,-2,0,2,4,6\}$ and $\mathrm{e}_{\mathrm{c}}=\{-6,-3,0,3,6\} . \mathrm{K}_{\mathrm{e}}$ and $\mathrm{K}_{\mathrm{c}}$ can be decided due to the actual error and its change ratio, so does $\Delta \mathrm{K}_{\mathrm{p}}, \Delta \mathrm{K}_{\mathrm{d}}$. The algorithm of updating $\mathrm{K}_{\mathrm{p}}$ and $K_{d}$ is shown in Fig.6.

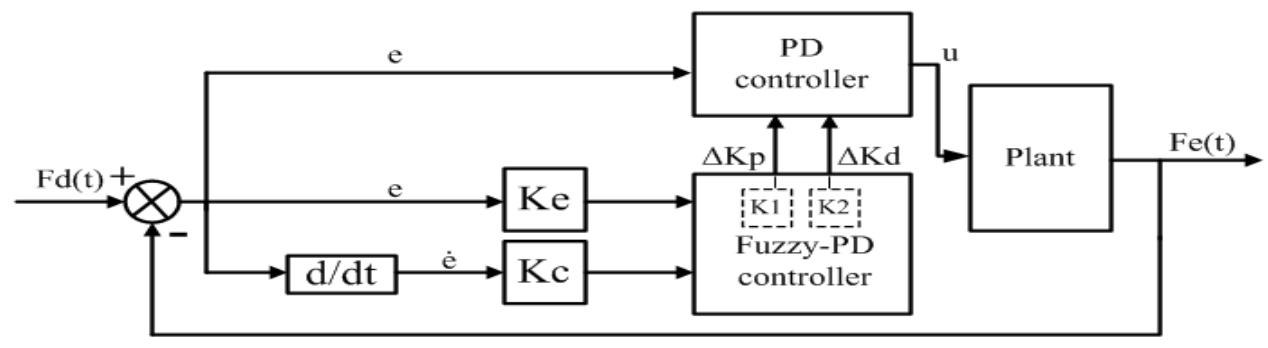

Fig. 5.The block diagram of the whole system

Establishment of Fuzzy Table. When the system detects a big tracking error and the error is still becoming bigger, the phenomenon means the actuator is responding slowly, and $K_{p}$ is in charge of adjusting the property of response speed, so $\mathrm{K}_{\mathrm{p}}$ should be set a big enough value, however, $\mathrm{K}_{\mathrm{d}}$ is in charge of regulating the fluctuating nature, if wants to increase the speed of response, $K_{d}$ must be set a smaller one, so the fuzzy rule can be expressed as if e equals to NB and $\mathrm{e}_{\mathrm{c}}$ equals to NB then the output $\Delta K_{p}$ should be $P B$, and the output $\Delta K_{d}$ should be NB. One can get $5 \times 7=35$ rules totally, and the fuzzy rule Table.I. and Table.II. consist of all these rules.

Establishment of the Membership Function. The performance characteristics of this system are that when the actual tracking-force is far from the desired force, the $\Delta \mathrm{K}_{\mathrm{p}}$ and $\Delta \mathrm{K}_{\mathrm{d}}$ values could change largely and they are relatively free in this case to regulate the system to respond faster, so 
the membership showed in Fig.7.(c), (d) is wider separately. While the actual tracking-force is approaching the desired force, it needs to avoid the excessive overshoot, therefore it is requested the membership function to be narrow in order to adjust this system precisely, as shown in Fig.7.(c), (d), so the outputs in this article make use of the non-uniform distribution membership functions. The values of the output of $\Delta \mathrm{K}_{\mathrm{p}}$ and $\Delta \mathrm{K}_{\mathrm{d}}$ can be changed by the parameters $\mathrm{K} 1$ and $\mathrm{K} 2$, which are in the controller, according to the experiments' requirements.

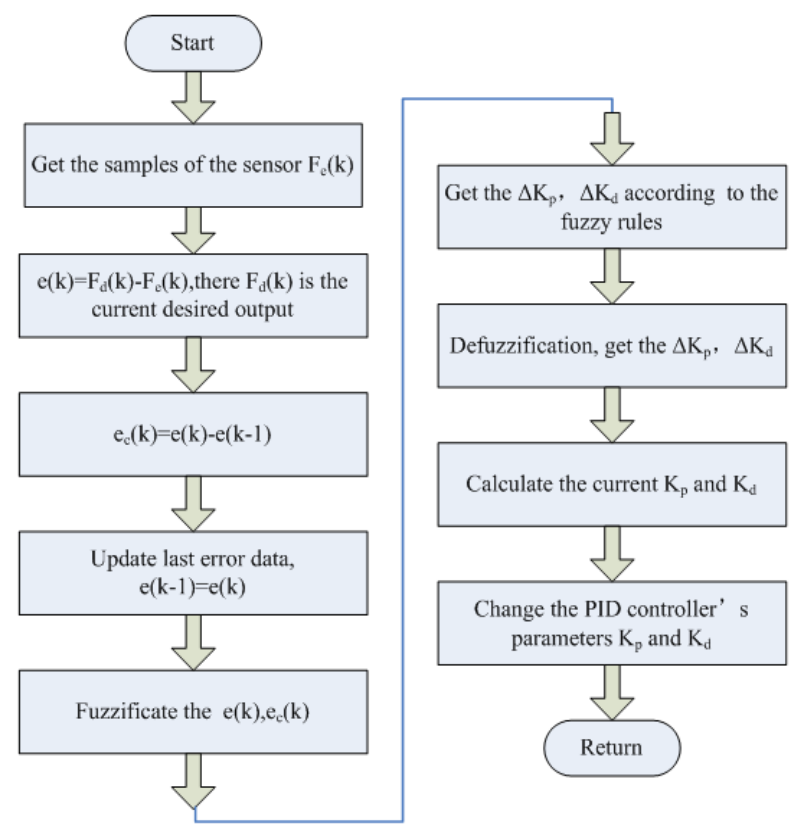

TABLE. I.

\begin{tabular}{|l|l|l|l|l|l|l|}
\hline \multirow{2}{*}{$\begin{array}{l}\text { Control } \\
\text { volume }\end{array}$} & \multicolumn{5}{|c|}{ Input (gain for ratio) $\Delta e$} \\
\cline { 2 - 7 } & NB & NS & ZO & PS & PB \\
\hline \multirow{4}{*}{$\begin{array}{l}\text { Input } \\
\text { (gain } \\
\text { for } \\
\text { error) } e\end{array}$} & NB & PB & PM & PM & PS & ZO \\
\cline { 2 - 7 } & NM & PB & PM & PS & PS & NS \\
\cline { 2 - 7 } & NS & PM & PM & PS & ZO & NS \\
\cline { 2 - 7 } & ZO & PM & PS & ZO & NS & NM \\
\cline { 2 - 7 } & PS & PS & ZO & NS & NS & ZO \\
\cline { 2 - 7 } & PM & PS & NS & NM & NM & NB \\
\cline { 2 - 7 } & PB & ZO & NM & NM & NM & NB \\
\hline \multicolumn{7}{|c|}{ TABLE. II. } \\
\hline
\end{tabular}

\begin{tabular}{|l|l|l|l|l|l|l|}
\hline \multirow{2}{*}{$\begin{array}{l}\text { Control } \\
\text { volume }\end{array}$} & \multicolumn{5}{|c|}{ Input (gain for ratio) $\Delta e$} \\
\cline { 2 - 7 } & $\mathrm{NB}$ & $\mathrm{NS}$ & $\mathrm{ZO}$ & $\mathrm{PS}$ & $\mathrm{PB}$ \\
\hline \multirow{4}{*}{$\begin{array}{l}\text { Input } \\
\text { (gain for } \\
\text { error) }\end{array}$} & $\mathrm{NB}$ & $\mathrm{PS}$ & $\mathrm{NB}$ & $\mathrm{NB}$ & $\mathrm{NB}$ & $\mathrm{PS}$ \\
\cline { 2 - 7 } & $\mathrm{NM}$ & $\mathrm{PS}$ & $\mathrm{NB}$ & $\mathrm{NM}$ & $\mathrm{NM}$ & $\mathrm{ZO}$ \\
\cline { 2 - 7 } & $\mathrm{ZO}$ & $\mathrm{ZO}$ & $\mathrm{NM}$ & $\mathrm{NM}$ & $\mathrm{NS}$ & $\mathrm{ZO}$ \\
\cline { 2 - 7 } & $\mathrm{PS}$ & $\mathrm{ZO}$ & $\mathrm{ZO}$ & $\mathrm{ZO}$ & $\mathrm{ZO}$ & $\mathrm{ZO}$ \\
\cline { 2 - 7 } & $\mathrm{PM}$ & $\mathrm{PB}$ & $\mathrm{PS}$ & $\mathrm{PS}$ & $\mathrm{PS}$ & $\mathrm{PB}$ \\
\cline { 2 - 7 } & $\mathrm{PB}$ & $\mathrm{PB}$ & $\mathrm{NM}$ & $\mathrm{PM}$ & $\mathrm{PS}$ & $\mathrm{PB}$ \\
\hline
\end{tabular}

Fig. 6. Algorithm of the Fuzzy-PID controller

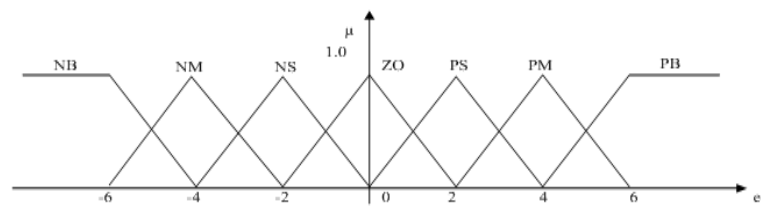

(a) Membership function of e

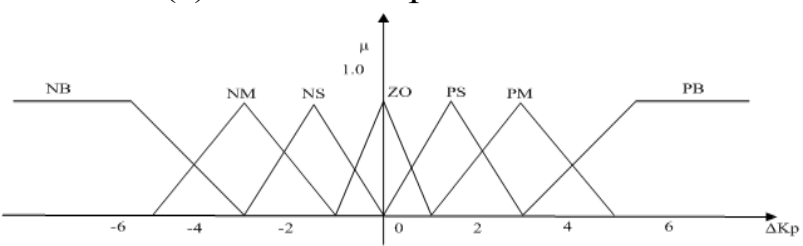

(c) Membership function of $\Delta \mathrm{K}_{\mathrm{p}}$

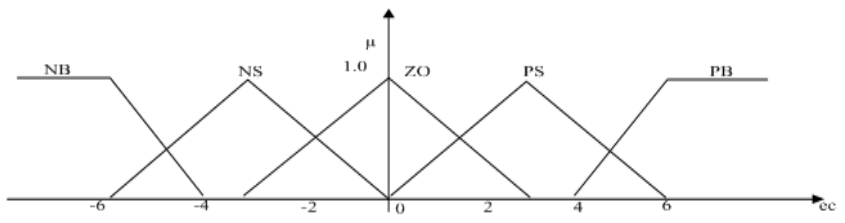

(b) Membership function of $\mathrm{e}_{\mathrm{c}}$

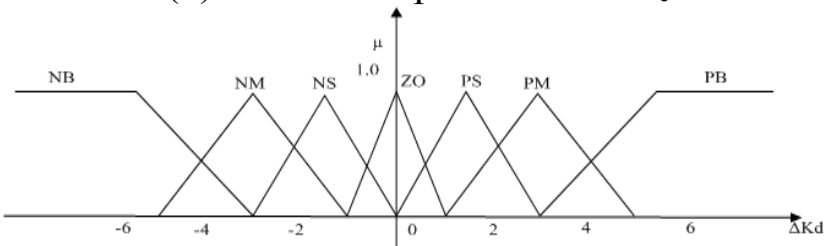

(d) Membership function of $\Delta \mathrm{K}_{\mathrm{d}}$

Fig. 7. Membership function of the Fuzzy-PID controller

Simulation of the Force-tracking System. In this paper, the fuzzy method is designed in the Fuzzy logic tool of MATLAB, the parameters $\mathrm{Ke}, \mathrm{Kc}, \mathrm{K} 1, \mathrm{~K} 2$ are set 10, 5, 8 and 0.5 separately, and the original valve of $K_{p}$ and $K_{d}$ are set as 120 and 20 according to the actual error and the outputs. The whole system of simulation is shown in Fig.8. and the simulation result is shown in Fig.9 which confirms that the Fuzzy-PID method has a better property of inputs-tracking. And the practical controller is carried out in LABVIEW system.

\section{Experimental System Set-up and the Force-Tracking Test}

Experimental Set-up. The experimental system, as shown in Fig.10, 11, is mainly consisted of one XYZ-positioning table (positioning accuracy is up-to $0.125 \mu \mathrm{m}$ ), one PIC MCU circuit with designed driving programs in it, one desktop PC with WINXP OS as a host computer and the corresponding control panel developed in the VC6.0, and the LABVIEW DAQ card ( PCI6221 16-bit A/D converter ) to acquire the signal $F_{e}$ generated by the PVDF sensor. 


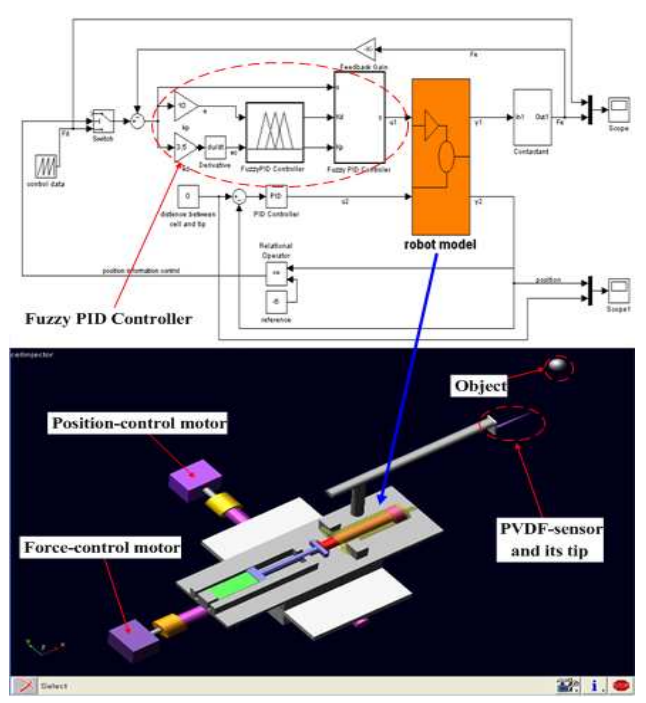

Fig. 8. Simulation of the whole tracking system

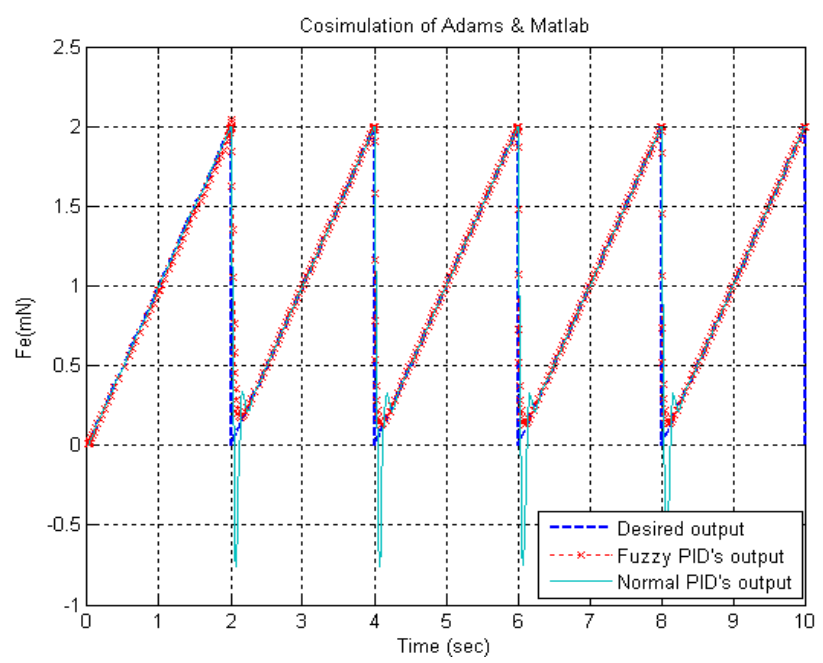

Fig. 9.Saw-signal-tracking result of Fuzzy-PID and normal PID controller

Process of the Test and its Results. During the experiment, $R_{2}=10 K \Omega, R_{3}=100 K \Omega, K=10$, and $50 \mathrm{HZ}$ low-pass filter, the parameters of PVDF film are the same as mentioned above. The PVDF sensor will move with the XYZ-positioning table controlled by the host computer and the sensor's tip will compact with a fixed soft ball, and then it will generate the actual force signal $\mathrm{F}_{\mathrm{e}}$ which will follow the given designed force signal $F_{d}$. In this paper two sets of test are carried out, one uses the ordinary PD control method and the other employs the Fuzzy-PID control method, and the original parameters $\mathrm{K}_{\mathrm{p}}, \mathrm{K}_{\mathrm{d}}$ are set as 120 and 20 separately.

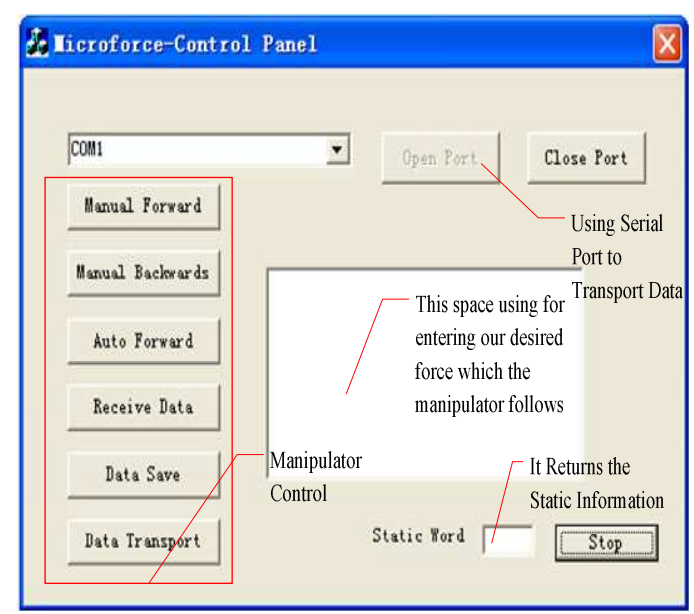

Fig. 10.The force-tracking control panel

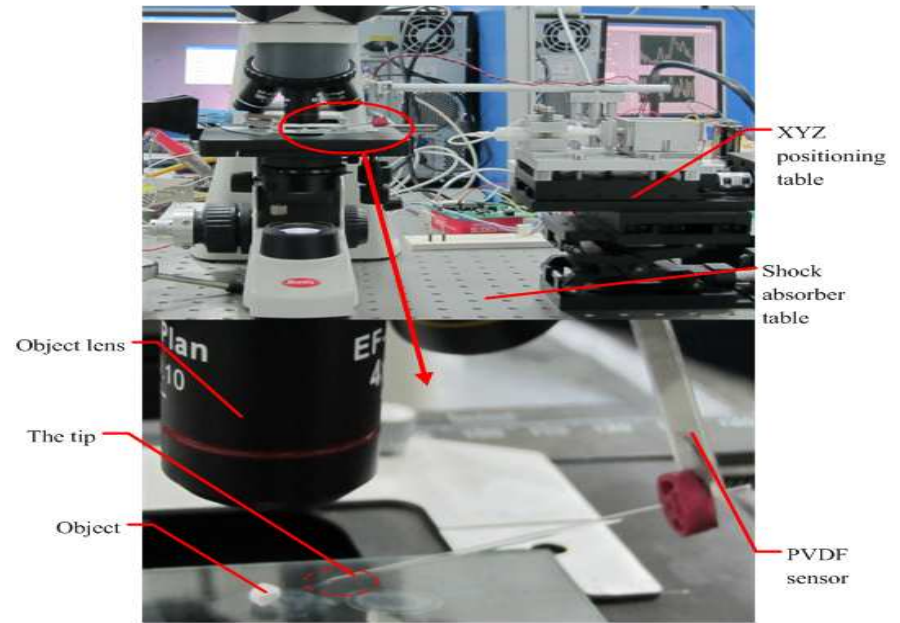

Fig. 11.The force-tracking system set-up

Let the system follow a desired saw signal and the test results are shown in Fig.12.(a), (b), the maximum force is $480 \mu \mathrm{N}$. The tracking results illustrate that Fuzzy-PD control method is better than the ordinary PD method in this micro-force-tracking system.

\section{Summary}

In this paper, based on the inverse-model control method, a static PVDF micro-force sensor has been developed and it possesses good properties such as high linearity, resolution and simple structure. Then a Fuzzy-PID controller has been designed and closed-loop control test has been carried out, it confirms that this force-tracking system is feasible in micro-force control fields. The next step we will carry out some cell-injection tests using this method and system. 


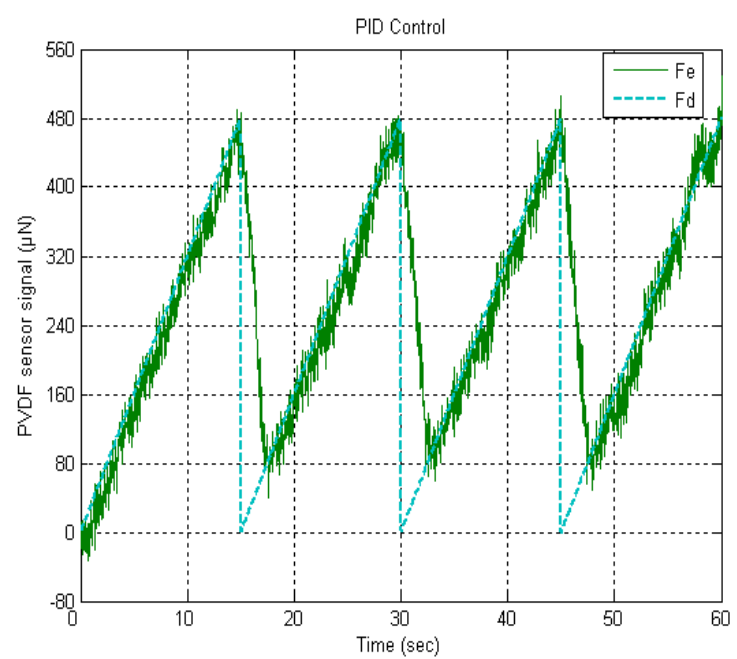

(a) Result of PD control method

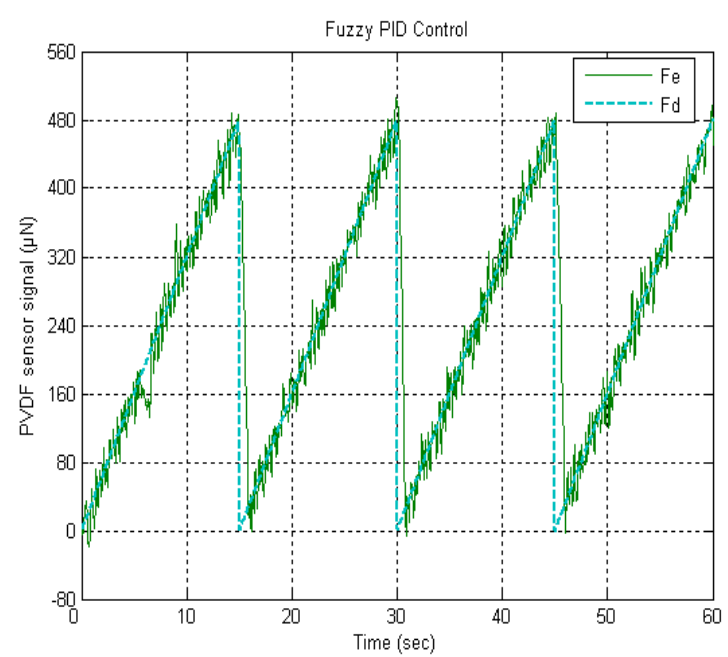

(b) Result of Fuzzy-PID control method

Fig. 12. Results of following a saw signal

\section{Acknowledgment}

This work is supported by The National High Technology Research and Development Program of China (2008AA04Z305), the National Nature Science Foundation of China under Grant 51075066, 985 Project of North eastern University of China and the State Key Laboratory of Robotics, (No. RL0200903).

\section{References}

[1] Haibo, H., et al. A Visual Impedance Force Control of A Robotic Cell Injection System. ROBIO '06. IEEE International Conference on 2006: 233-238

[2] Sung-Yong, C. and S. Jae-Hong. A new micro biological cell injection system. Proceedings. 2004 IEEE/RSJ International Conference on 2004: 1642-1647

[3] Zesch, W. and R.S. Fearing, Alignment of microparts using force controlled pushing. Microrobotics and Micromanipulation, 1998. 3519: 148-156.

[4] Yantao, S., et al. A high sensitivity force sensor for microassembly: design and experiments. 2003. AIM 2003. Proceedings. 2003 IEEE/ASME International Conference on 2003: 703-708

[5] Yu, X., et al. A force control based cell injection approach in a bio-robotics system. ICRA '09. IEEE International Conference on 2009: 3443-3448

[6] Zhiyong, S., et al. A PVDF Micro-force Sensor Based on Inverse-model Algorithm and Its Applications. ICIA IEEE International Conference on 2011: 801-806

[7] Hao, L. and Z. Li, Modeling and adaptive inverse control of hysteresis and creep in ionic polymer-metal composite actuators. Smart Materials and Structures, 2010. 19(2): 025014

[8] Li, Z., L.N. Hao, Adaptive Inverse Control Based on the Creep Property of IPMC. Ccdc 2009 Vols 1-6, Proceedings, New York: 702-706

[9] Yantao, S., X. Ning, and W.J. Li. Dynamic force measurement for microassembly of surface MEMS structures. ROBIO 2005 IEEE International Conference on. 2005: 646-651

[10] Pillarisetti, A., et al., Evaluating the Effect of Force Feedback in Cell Injection. Automation Science and Engineering, IEEE Transactions on, 2007. 4(3): 322-331. 